\title{
1 A Governance Framework for Development and Assessment of 2 National Action Plans on Antimicrobial Resistance
}

\author{
3 Michael Anderson, ${ }^{1}$ Kai Schulze, $, 1,2$ Alessandro Cassini, ${ }^{3}$ Diamantis Plachouras, ${ }^{3}$ Elias Mossialos ${ }^{1}$ \\ 4 1. LSE Health, Department of Health Policy, London School of Economics and Political Science \\ 5 2. MRC Epidemiology Unit, University of Cambridge \\ 6 3. European Centre for Disease Prevention and Control
}

7

8

\section{Summary}

Strengthening governance is an essential strategy to tackling antimicrobial resistance (AMR) at all levels; global, national, regional and local. To date, no systematic approach to governance of AMR national action plans (NAPs) exists. To address this, we aimed to develop the first governance framework to offer guidance for both the development and assessment of AMR national action plans (NAPs). We reviewed health system governance framework reviews to inform the basic structure of our framework, international guidance documents from the WHO, FAO, OIE and the EU, and sought the input of over 25 experts from international organizations, government ministries, policy institutes and academic institutions to develop and refine our framework. The framework consists of 18 domains with 52 indicators that are contained within three governance areas: "policy design", "implementation tools", and "monitoring and evaluation". To consider the dynamic nature of AMR, the framework is conceptualized as a cyclical process, which is responsive to the context and allows for continuous improvement and adaptation of AMR NAPs.

\section{Key messages}

- Antimicrobial Resistance (AMR) is one of the most pressing and complex issues today, with multi drug-resistant, extensively drug-resistant, and even pan drug-resistant organisms emerging.

- AMR is driven by inter-related dynamics in the human, animal, and environmental health sectors, which makes governance challenging.

- Strengthening governance of AMR policies at all levels; global, national, regional and local, is essential to tackling AMR. To date, no comprehensive framework for the governance of AMR National Action Plans (NAPs) has been developed.

- To our knowledge, this is the first study that has developed a governance framework for AMR NAPs, based on a systematic review of the literature, international guidance, and over 20 experts from various international organizations, government ministries, policy institutes and academic institutions

- The framework is conceptualized as a cyclical process between the three governance areas; policy design, implementation tools, and monitoring and evaluation.

- Within policy design, improving strategic vision, coordination, participation, accountability, responsibility, sustainability, and equity were identified as key to strengthening governance.

- Implementation, surveillance, antimicrobial stewardship, infection prevention and control, education, public awareness, medicines regulation, and fostering R\&D and facilitating market access to novel products were all identified as essential tools.

- To ensure NAPs can adapt and continually improve, feedback mechanisms, reporting and research to understand the drivers of AMR, were identified as crucial components to allow monitoring and evaluation. 
48

49 Words: 3274 excluding tables and figures. AMR NAPS.
- To build on this governance framework, there is a need for international leadership to develop consensus and engagement from national policy-makers to strengthen governance in

50 
52

The problem of antimicrobial resistance (AMR) is one of the most pressing and complex current public health issues. Today, multi drug-resistant, extensively drug-resistant, and even pan drug-resistant organisms are a challenge for healthcare-systems of varying stages of development. If not combatted timely and effectively, AMR can potentially lead to millions of preventable deaths per year and to hundreds of billions of economic costs annually, due to losses in international trade or livestock production and increased healthcare expenditure. ${ }^{1}$ Following the adoption of the Global Action Plan on AMR by the World Health Assembly in 2015, ${ }^{2}$ many countries have refined or developed their AMR national action plans (NAPs) in accordance with the internationally recognized 'One Health' approach which requires policies to be developed and implemented inter-sectorally across human, animal, and environmental health. Here, we present an AMR governance framework with a dual purpose: as a tool for policy-makers to both develop and improve AMR NAPs, and to also facilitate an objective assessment of AMR NAPs to increase accountability.

\section{Defining Governance}

Definitions of governance have their origins in the multilateral development institutions of the late 1980 s and 1990s. However, defining governance remains challenging and complex. It is helpful to start by defining what governance is not, i.e. it is not synonymous with government. Addressing governance issues therefore does not exclusively rest on actions of governments, but also on other societal organizations, how they relate to the public, and how decisions are taken. ${ }^{3}$ Various efforts to define governance have been undertaken and two widely referenced definitions have been outlined by the United Nations Development Programme (UNDP) and the WHO. The UNDP encompasses "five good governance principles": legitimacy and vote, direction, performance, accountability, and fairness. ${ }^{4}$ The definition recognizes that these principles sometimes overlap and might even be conflicting, their implementation is dependent on the context, the application of these principles is complex, and that good governance needs to consider how power is exercised.

Beside this more general definition, governance has been defined more explicitly from a health-systems perspective, starting with the World Health Report 2000. ${ }^{5}$ Here, governance is discussed as a form of stewardship, seen as "the careful and responsible management of the well-being of the population". The role of the government is outlined as one of "oversight and trusteeship", which requires "vision, intelligence and influence". In 2002, the WHO defined governance further by outlining six domains or sub-functions; generation of intelligence, formulating strategic policy direction, ensuring tools for implementation (powers, incentives and sanctions), building coalitions / partnerships, ensuring a fit between policy objectives and organizational structure and culture, and ensuring accountability. ${ }^{6}$ Later, within the 2007 WHO Framework for Action, these principles were cemented as one of the six key building blocks of a health system, ${ }^{7}$ under the domain of 'leadership and governance'.

\section{Governance in the context of AMR National Action Plans}

Understanding what good governance translates to within the context of AMR national action plans is a different matter. The complex nature of the emergence and spread of AMR globally and the politicaleconomic features of health systems pose challenges that mandate effective governance for successful implementation of AMR policies. ${ }^{8,9}$ AMR is driven by inter-related dynamics in the human, animal, and environmental health sectors, so actions to address AMR should include mechanisms that coordinate AMR policy inter-sectorally. Previous lack of international agreement regarding the direction of efforts to tackle AMR has allowed the discussion to be shaped by a "war on superbugs" or "post-antibiotic apocalypse" discourse, which has put much emphasis on the discovery of new antimicrobials through pharmaceutical innovation and too little priority on reduction of antimicrobial use, and on prevention 
and control of infections. Furthermore, the complexity of AMR also necessitates policies that range in diversity from surveillance, awareness, to regulation, stewardship, and infection prevention and control, each in the context of human, animal, and environmental health.

Given these challenges, there has been considerable interest in governance within AMR policy. In an analysis of AMR policies in 29 European Union/European Economic Area (EU/EEA) countries, the Third Report on Implementation of the Council Recommendation on prudent use of antimicrobial agents in human medicine suggested the need for prioritising governance within national policies to contain AMR. ${ }^{10}$ The Food and Agriculture Organization of the United Nations (FAO), the World Organisation for Animal Health (OIE) and the World Health Organization (WHO) together form a tripartite which has produced a manual for developing NAPs on AMR that emphasizes the establishment of a governance mechanism and the undertaking of a thorough situational analysis as key for the development of NAPs. ${ }^{11}$ The global tripartite database on country progress has been a first step towards monitoring AMR NAPs on a global scale. ${ }^{12}$ The goal of the database is to provide "baseline information on the status of countries" regarding the implementation of the Global Action Plan and actions to address AMR across all sectors. It provides crucial initial information such as the existence of a 'One Health' NAP, surveillance of antibiotic use in human and animal health, training of veterinary and health personnel and the presence of public awareness campaigns, although to date its data collection is broad and lacks detail.

In 2018, a discussion paper on AMR NAPs from the Interagency Coordination Group on Antimicrobial Resistance (IACG) has concluded that in most countries, the greatest challenge is not writing a NAP but implementing it and demonstrating sustained action, and that the following factors make the implementation of NAPs particularly difficult: awareness and political will, finance, coordination, monitoring and data and technical capacity. ${ }^{13}$ The IACG framework for action, ${ }^{14}$ highlights system strengthening, governance, coordination, coalition building and political commitment as key enablers for sustainable action at both global and national levels. In the IACG's final report to the secretarygeneral of the United Nations (UN), ${ }^{15}$ the need to accelerate the development and implementation of One Health AMR NAPs is again highlighted. The IACG rightly emphasises that strengthening governance at all levels of AMR policy; global, national, regional and local, is essential to tackling AMR. Linking global and national governance, the IACG has recommended that tripartite agencies strengthen One Health actions based on country priorities and needs supported by the urgent establishment of a "One Health Global Leadership Group" on AMR. ${ }^{15}$ The IACG has also recommended that the UN secretary-general, in close collaboration with the tripartite agencies, UN Environment and other international organizations, convene an independent panel on evidence for action against AMR to support member states to develop evidence based policies. ${ }^{15}$

In summary, the inherent complexities of the drivers of AMR demand a systematic approach to governance. However, to date, no comprehensive framework for the governance of NAPs has been developed and there is a need for increased clarity in this area. To address this unmet need, this paper presents the development of an AMR governance framework for NAPs and the methods used during its development.

\section{Methods}

We approached the objectives in four stages (Table 1). First, we searched Medline, EMBASE, and Global Health databases to identify pre-existing AMR governance frameworks. We then performed a second search of systematic and non-systematic reviews of health-related governance frameworks again searching Medline, EMBASE, and Global Health databases to inform the initial development of the framework. To be included, the publications had to provide sufficient information on the domains within the frameworks included and had to be related to health. We choose to analyse systematic and 
142 non-systematic reviews as health system governance is a previously well-researched area, and this 143 strategy allowed us to comprehensively review a large body of evidence in an efficient manner. Both 144 searches were performed up to $30^{\text {th }}$ April 2018; their search strategies can be found in the 145 supplementary material.

146 Data was abstracted from each identified framework using a standardized extraction form. The 147 following information was collected: 1) first author name; 2) year and country of publication; 3) name 148 of the framework; and 4) all domains that constitute the framework. The search and data extraction 149 process were independently performed and agreed upon by the co-authors. We included domains in 150 the initial framework if they were included in more than a third of the frameworks reviewed (appendix 151 A). This approach was taken to capture the most commonly utilised governance principles, and the co152 author's judged the cut-off value to be high enough to provide sufficient inclusiveness.

153

154

155 
Table 1. Stages of Developing and Refining the AMR Governance Framework.

\begin{tabular}{|c|c|c|c|}
\hline STAGE & AIMS & \multicolumn{2}{|c|}{ METHODS USED } \\
\hline $\begin{array}{l}\text { I. Search for } \\
\text { existing AMR } \\
\text { governance } \\
\text { frameworks }\end{array}$ & $\begin{array}{l}\text { To identify previously } \\
\text { published AMR } \\
\text { governance } \\
\text { frameworks }\end{array}$ & \multicolumn{2}{|c|}{$\begin{array}{l}\text { Search of Google Scholar, Medline, Embase, Global Health } \\
\text { using the search terms "antimicrobial", "antimicrobic", } \\
\text { "antibiotic", "antibacterial", and "governance". } \\
\text { Academic publications, reports, and grey literature } \\
\text { considered }\end{array}$} \\
\hline $\begin{array}{l}\text { II. Systematic } \\
\text { review of } \\
\text { health system } \\
\text { governance } \\
\text { framework } \\
\text { reviews }\end{array}$ & $\begin{array}{l}\text { To identify previously } \\
\text { published health } \\
\text { system governance } \\
\text { frameworks }\end{array}$ & \multicolumn{2}{|c|}{$\begin{array}{l}\text { Search of the literature using Medline, Embase, Global } \\
\text { Health using the search terms "governance", and } \\
\text { "framework". } \\
\text { Academic publications, reports, and grey literature } \\
\text { considered }\end{array}$} \\
\hline $\begin{array}{l}\text { III. Review of } \\
\text { international } \\
\text { guidance } \\
\text { documents }\end{array}$ & $\begin{array}{l}\text { To identify all } \\
\text { relevant policy } \\
\text { options and } \\
\text { strategies } \\
\text { To ensure } \\
\text { comprehensiveness } \\
\text { of implementation } \\
\text { tools }\end{array}$ & \multicolumn{2}{|c|}{$\begin{array}{l}\text { Review of key international guidance documents: } \\
\text { - WHO: Global Action Plan on Antimicrobial Resistance } \\
(2015)^{2} \\
\text { - The OIE Strategy on Antimicrobial Resistance and the } \\
\text { Prudent Use of Antimicrobials (2016) } \\
\text { - The FAO Action Plan on Antimicrobial Resistance 2016- } \\
2020(2016)^{17} \\
\text { - FAO/OIE/WHO: A Manual for developing National } \\
\text { Action Plans (2016) } \\
\text { EU: A European One Health Action Plan against } \\
\text { Antimicrobial Resistance (2017) }\end{array}$} \\
\hline $\begin{array}{l}\text { IV. Expert } \\
\text { review of draft } \\
\text { framework } \\
\text { and synthesis }\end{array}$ & $\begin{array}{l}\text { To expand and revise } \\
\text { the domains and } \\
\text { indicators in all } \\
\text { governance areas } \\
\text { To validate the } \\
\text { framework and } \\
\text { potential value for a } \\
\text { range of stakeholders } \\
\text { To refine and } \\
\text { propose final } \\
\text { framework }\end{array}$ & $\begin{array}{l}\text { Experts consulted from: } \\
5 \text { International Organizations } \\
8 \text { Government Departments } \\
8 \text { Universities } \\
2 \text { Policy Institutes } \\
10 \text { Countries } \\
5 \text { Continents } \\
\text { (See Supplementary Material) }\end{array}$ & $\begin{array}{l}\text { Expert consultations through: } \\
\text { Written review feedback } \\
\text { Teleconferences }\end{array}$ \\
\hline
\end{tabular}

*WHO, World Health Organization; **OECD, Organisation for Economic Co-operation and Development; ***LSE, London 
To account for the distinctive aspects of governance in the context of national AMR policy, we expanded and refined the AMR governance framework in the third stage by reviewing the five most recent guidance documents from four key international organizations - the WHO, the OIE, the FAO as well as the EU. These four organisations are major actors in international AMR policy development and have a precedent of producing guidance regarding national AMR policies for their member states.

To increase the validity of the framework and to develop pre-existing and additional indicators we sought review of the framework and its components by experts from multiple sectors, disciplines, and geographies in the fourth stage. A judgement sample was used for this purpose. ${ }^{19}$ Experts were approached based on a combination of factors such as the length of their experience in the field of AMR, their wide perspective on the development of AMR NAPs (both policy-makers and academics), and their interest in governance challenges associated with AMR policy. In total, a range of experts from five international or intergovernmental organisations (WHO, PAHO, OECD, European Commission, European Centre for Disease Prevention and Control), eight universities, eight government ministries, and two policy institutes (Chatham House and PEW Charitable Trust) provided feedback (see acknowledgements). The final step of stage IV involved synthesizing the feedback and findings from the preceding steps to produce a refined and final framework.

\section{Results}

Stages I and II: Systematic review of AMR governance frameworks and health system governance framework reviews

The main results of all stages are summarized in Table 2. The systematic search for previous AMR governance frameworks yielded no results (see supplementary material). The process of identification and study selection for the systematic review of health system governance reviews is summarized in Figure 1.

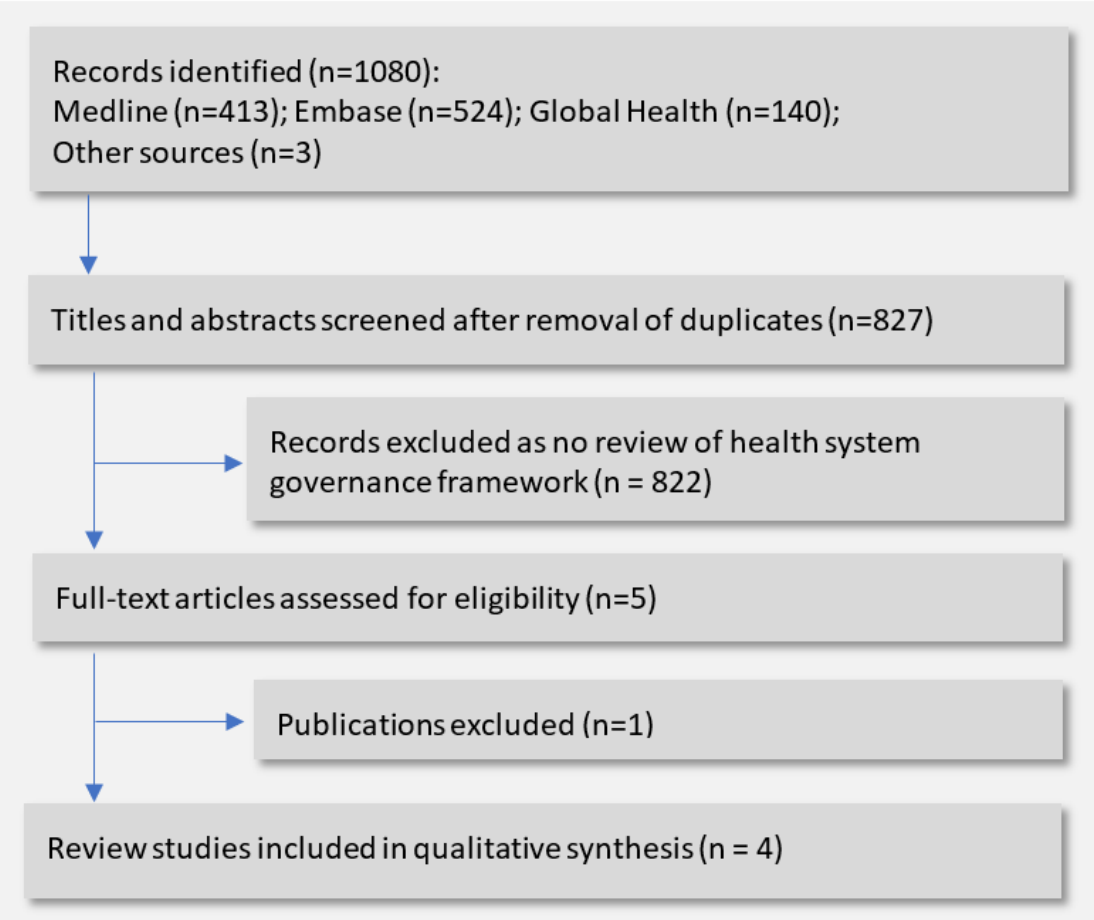

Figure 1. Flow chart of study selection (stage II)

From a total of 827 records that were title- and abstract-screened, 822 were excluded as they were not reviews of health system governance frameworks. The full text of the remaining four publications were 
reviewed, leading to the inclusion of three non-systematic reviews and one systematic review for qualitative assessment.20-23 Twenty-six governance frameworks were identified in those four publications and the 11 most frequent key governance domains across these frameworks were identified. The criteria for the inclusion of commonly used governance domains were present in more than a third of governance frameworks, a cut-off agreed upon by consensus of co-authors (supplementary material). The final component of stage II was the formation of the basic structure of the framework by grouping these eleven domains in three broader governance areas: 'Policy Design', 'Implementation tools', and 'Monitoring and Evaluation'.

Table 2. Summary of development of the AMR Governance Framework

\begin{tabular}{|c|c|c|}
\hline STAGE & \multicolumn{2}{|r|}{ MAIN RESULTS } \\
\hline $\begin{array}{l}\text { I. Search for existing AMR } \\
\text { governance frameworks }\end{array}$ & \multicolumn{2}{|c|}{ No AMR governance frameworks identified } \\
\hline \multirow[t]{4}{*}{$\begin{array}{l}\text { II. Systematic review of } \\
\text { health system governance } \\
\text { reviews }\end{array}$} & \multicolumn{2}{|c|}{$\begin{array}{l}\text { Review of } 26 \text { health system governance frameworks } \rightarrow \text { Basic structure of } \\
\text { AMR governance framework ( } 3 \text { governance areas, } 11 \text { governance } \\
\text { domains): }\end{array}$} \\
\hline & $\begin{array}{l}\text { Area } \\
\text { Policy design }\end{array}$ & $\begin{array}{l}\text { Domains } \\
\text { Strategic Vision, Participation, Coordination, } \\
\text { Accountability, Transparency, Sustainability, } \\
\text { Equity }\end{array}$ \\
\hline & Implementation tools & $\begin{array}{l}\text { Generation of Information and Intelligence, } \\
\text { Regulation }\end{array}$ \\
\hline & Monitoring and evaluation & Effectiveness, Responsiveness \\
\hline $\begin{array}{l}\text { III. Review of international } \\
\text { guidance documents }\end{array}$ & \multicolumn{2}{|c|}{$\begin{array}{l}\text { Domains } \\
\text { - } 7 \text { domains added: Surveillance, Stewardship, Infection Prevention and } \\
\text { Control, Education, Public Awareness, Fostering R\&D of Novel } \\
\text { Antimicrobials/Alternatives, AMR Research } \\
\text { - } \quad \text { One domain removed: Generation of Information and Intelligence. } \\
\text { Replaced by the following domains: Surveillance, AMR research, and } \\
\text { Fostering of R\&D of Antimicrobials/Alternatives } \\
\text { Indicators } \\
\text { - } 34 \text { indicators developed (see supplementary material) }\end{array}$} \\
\hline $\begin{array}{l}\text { IV. Expert review of draft } \\
\text { framework and synthesis }\end{array}$ & \multicolumn{2}{|c|}{$\begin{array}{l}\text { Domains } \\
\text { - } 4 \text { domains renamed: Antimicrobial Stewardship, Medicines } \\
\text { Regulation, Feedback Mechanisms, Fostering R\&D and Facilitating } \\
\text { Market Access to Novel Products } \\
\text { - } \quad \text { One domain added: Reporting } \\
\text { Indicators } \\
\text { - } 34 \text { indicators reformulated/reworded and explanatory text added } \\
\text { - } \quad 18 \text { indicators added } \\
\text { Agreement on basic structure of the framework }\end{array}$} \\
\hline
\end{tabular}


198 Reviewing the five international guidance documents resulted in the addition of seven domains: 199 'Surveillance', 'Stewardship', 'Infection Prevention and Control', 'Education', 'Public Awareness',

200 'Fostering the research and development (R\&D) of Novel Antimicrobials/Alternatives', 'AMR Research', 201 some of which replaced the previous domain; 'Generation of Information and Intelligence' as well as the extraction of 34 initial indicators (see supplementary material). These domains and indicators were selected as the first step towards developing a governance framework for the specific context of AMR NAPs.

205 The wording of the indicators was selected in such a way that they could offer binary answers and be applied using a combination of publicly available resources and interviews of country experts to allow a feasible and practical application of the framework to a country's AMR NAP. The justification for each of these indicators is explored further within the framework.

Stage IV: Expert review of draft framework and synthesis

210 Throughout several iterations of the governance framework, we received expert feedback via email and 211 teleconferences. In three cases we received consolidated feedback based on the responses of multiple individuals in those organizations (see acknowledgements). The experts agreed on the general structure of three governance areas and most domains. Instead, experts primarily focused their feedback on the improvement and development of the indicators. This resulted in the reformulation and rewording of initial 34 indicators, the addition of 18 further indicators as well as the addition of one further domain ('Reporting') to feed into the final 'AMR Governance Framework'.

\section{Governance Framework}

218 Eighteen separate domains were incorporated into the framework within three governance areas: 219 'Policy Design', 'Implementation Mechanisms', and 'Monitoring and Evaluation' (Figure 2). At the structural level, the framework represents an ongoing cycle of review and evaluation processes. The aim of this cyclical design is to conceptualize AMR governance not as a static but dynamic and ongoing process that constantly improves and adjusts, according to lessons learned from monitoring and evaluation. 


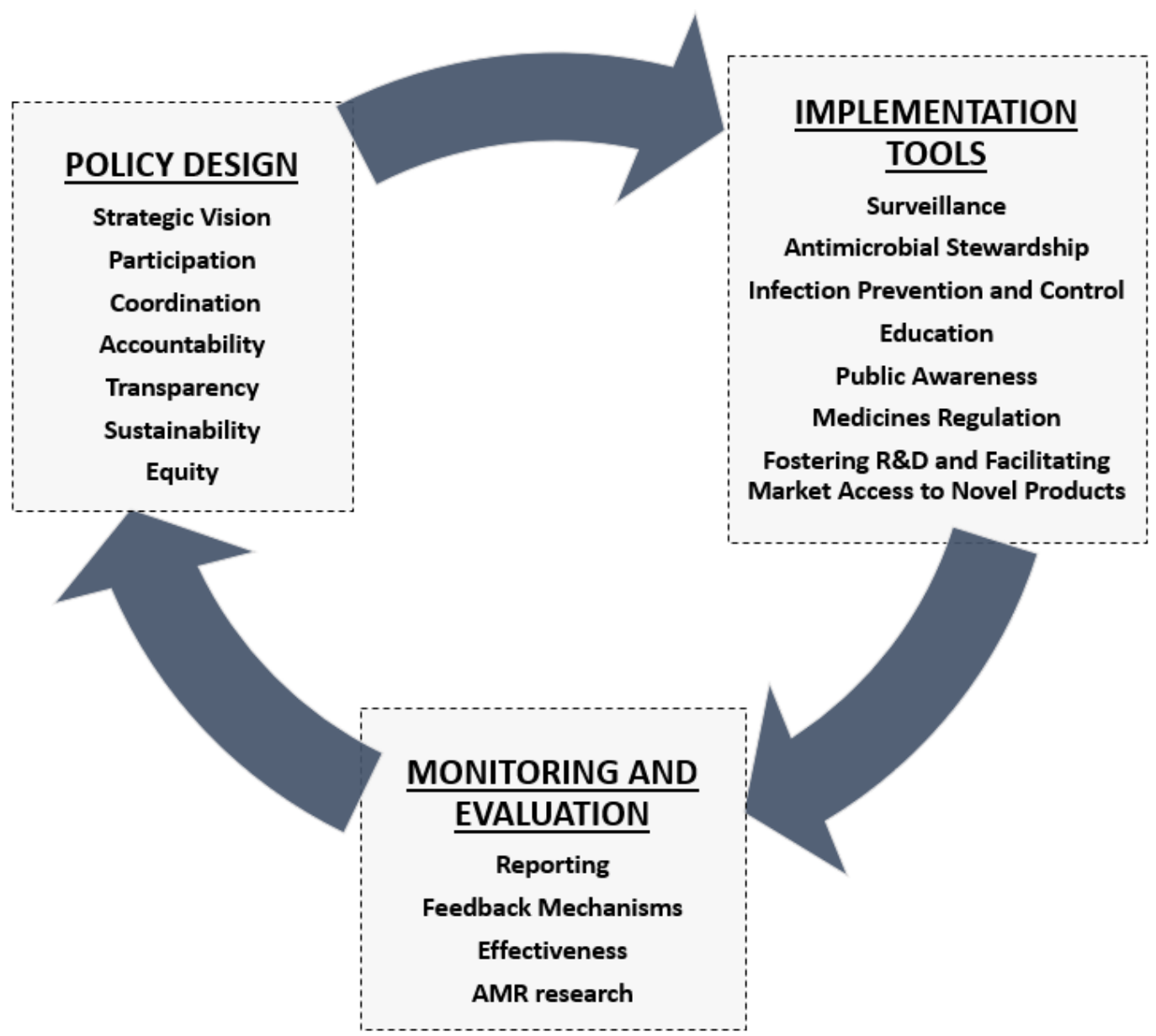

Figure 2 AMR governance framework: three areas and 18 domains.

The first governance area - 'Policy design' - is concerned with general and procedural issues of AMR NAPs, such as wide participation in the development of NAPs, coordination across the multiple sectors, and levels of service delivery (at national and sub-national levels), transparency, sustainability and equity implications of AMR policies as well as determining who is ultimately accountable to the government for achieving the objectives of the NAP (Table 3 ).

The second governance area - 'Implementation tools' - consists of crucial interventions contained within WHO/FAO/OIE/EU guidance. Here, three of the domains determine whether surveillance, antimicrobial stewardship programmes, and infection prevention and control measures are implemented across the 'One Health' spectrum. Other domains in this governance area encompass further fundamental AMR tools such as education of relevant professionals, public awareness activities, and medicines regulation. 'Implementation tools' also examine whether there are appropriate policies and incentives in place to encourage research and development of novel antimicrobials and alternatives (Table 4).

Domains within the third governance area - 'Monitoring and Evaluation' - include reporting and feedback mechanisms that allow for regular review and evaluation of AMR NAPs, as well as the effectiveness and cost-effectiveness dimensions of different aspects of the NAPs. Finally, the nontherapeutic AMR research domain considers whether there is a national multidisciplinary 'One Health' research agenda which aims to understand the drivers of and potential strategies to combat AMR (Table 5). 
For each of the 18 domains, multiple indicators were developed to signal whether the requirements for the domains are fulfilled. In total, 52 indicators were derived and are outlined in detail, including an explanation of their rationale in Tables $3-5$. 


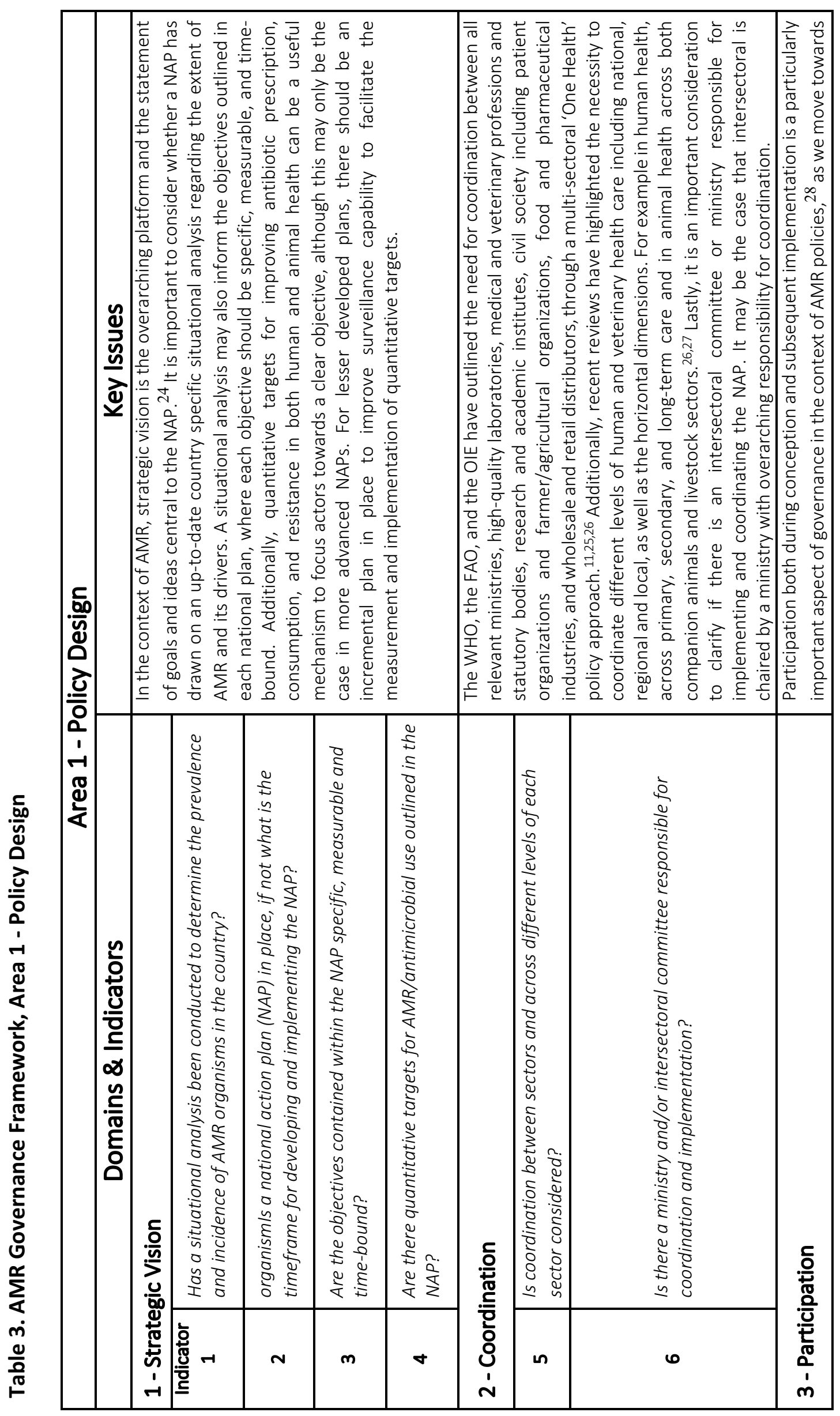




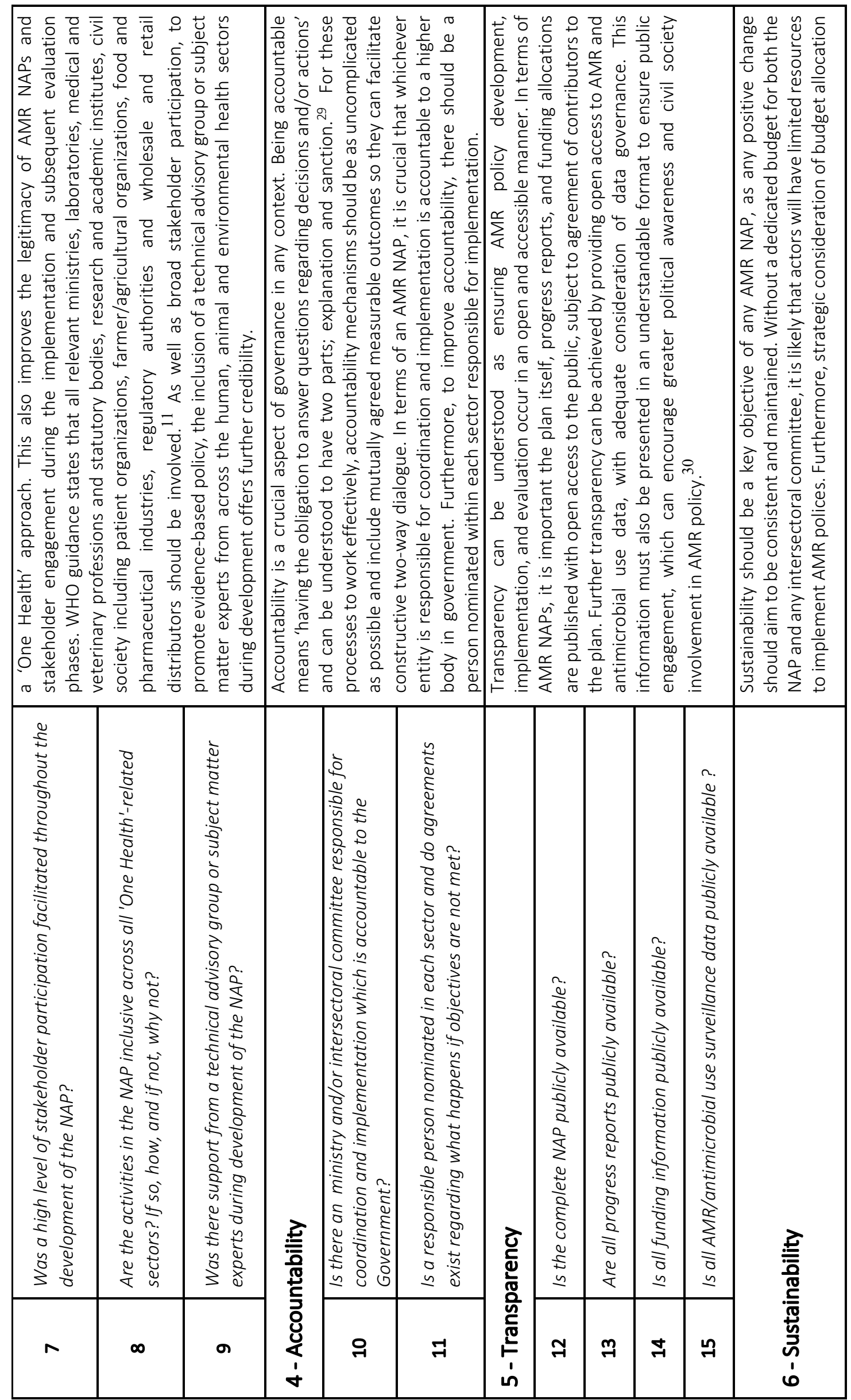




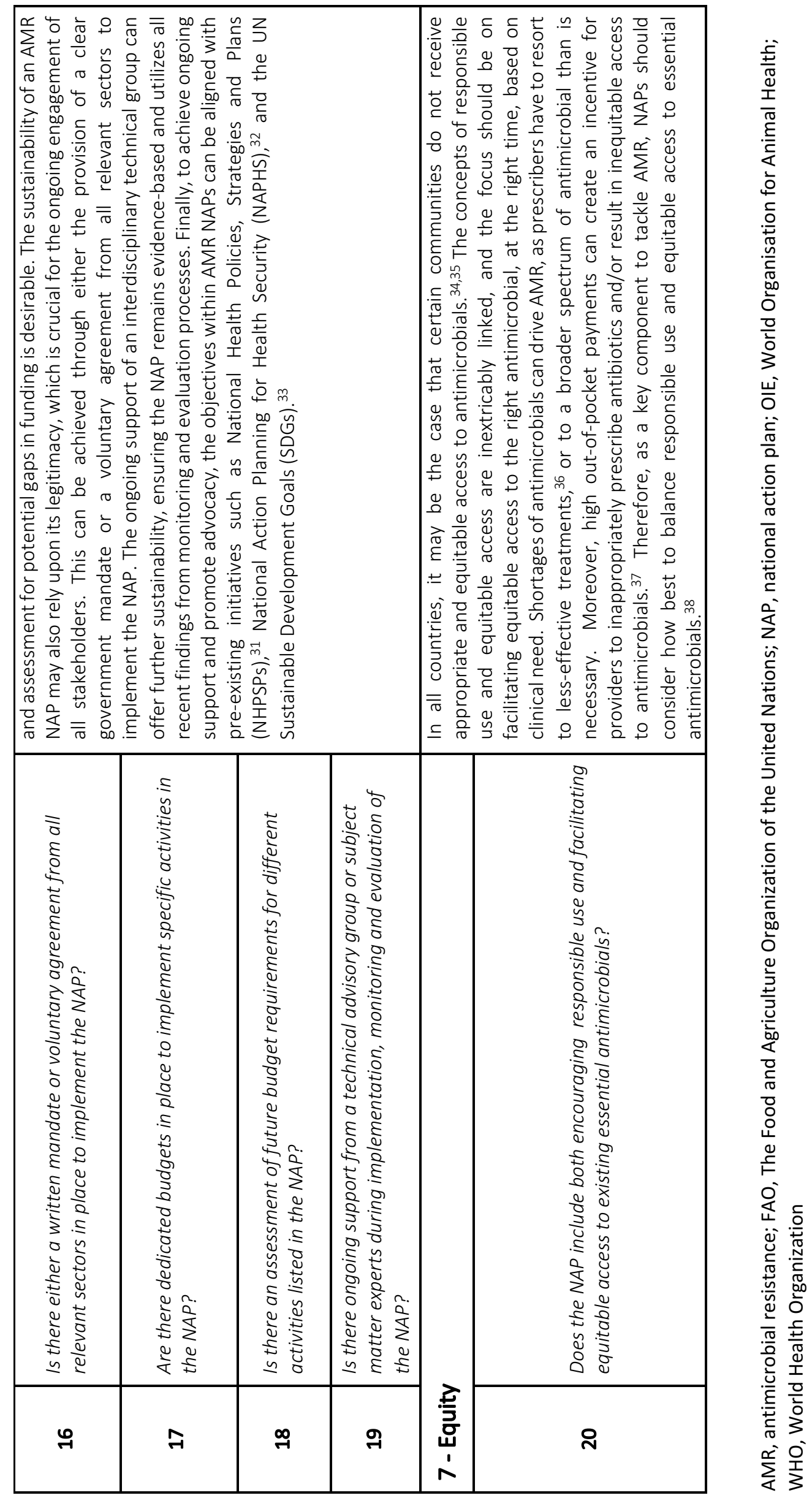




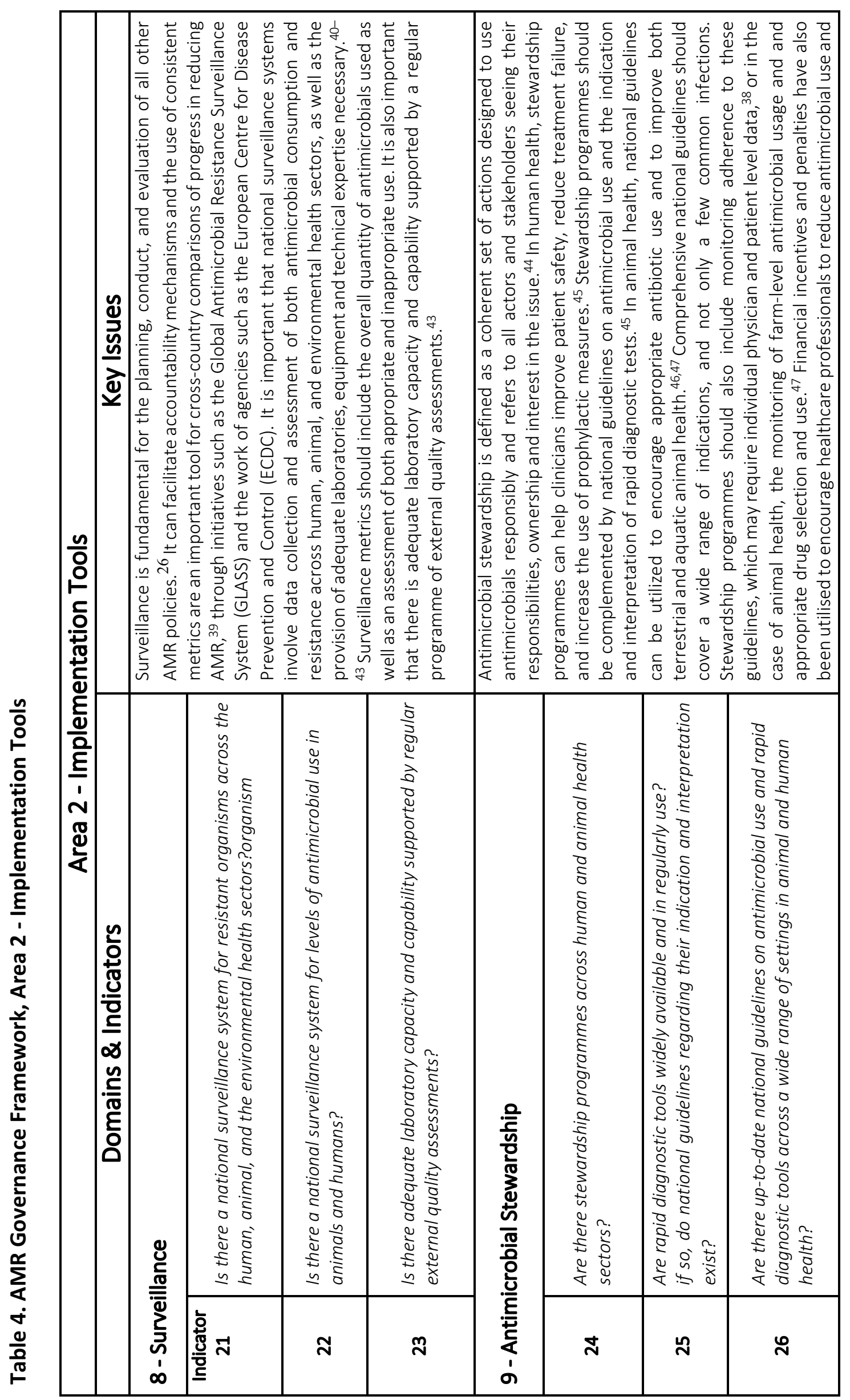




\begin{tabular}{|c|c|c|c|c|c|c|c|}
\hline 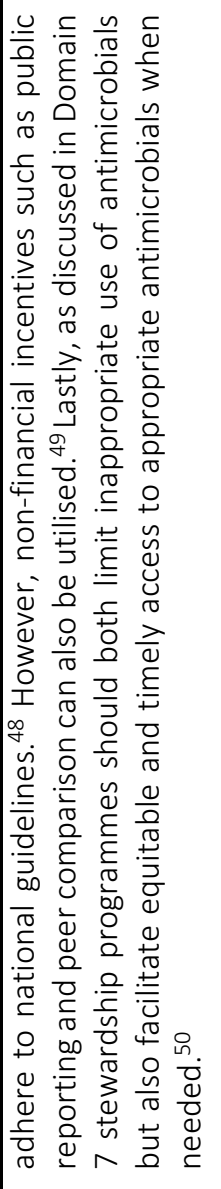 & \multicolumn{5}{|c|}{ 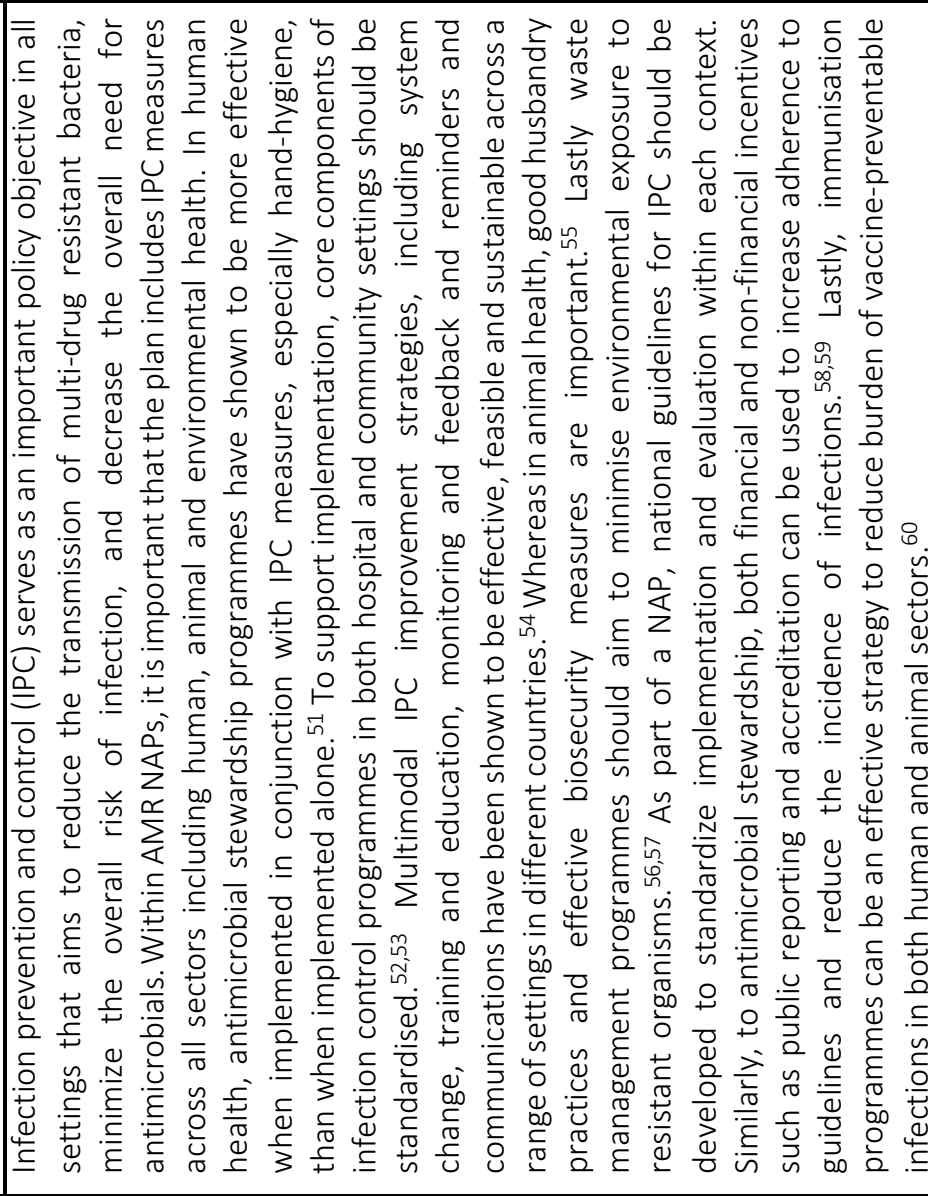 } & \multicolumn{2}{|c|}{ 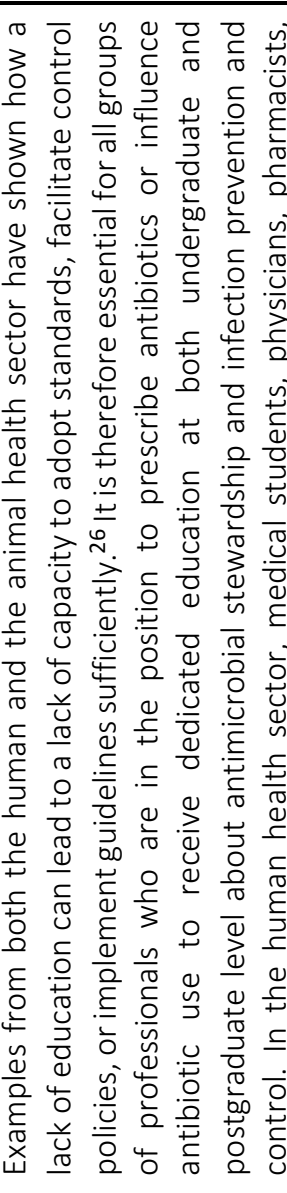 } \\
\hline 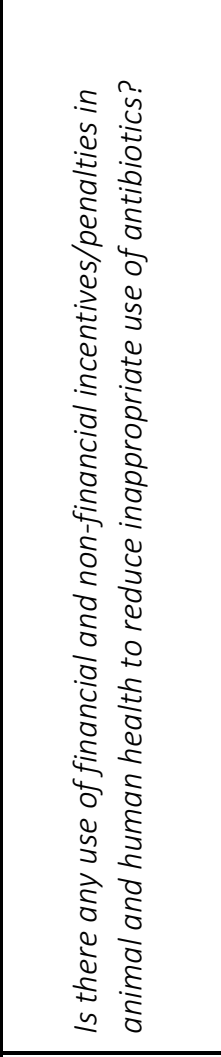 & \multirow{2}{*}{ 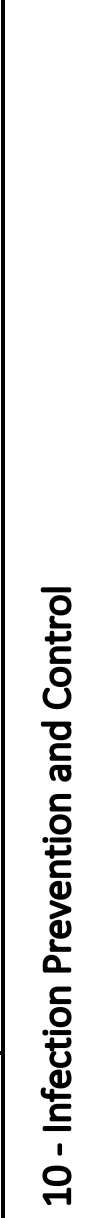 } & 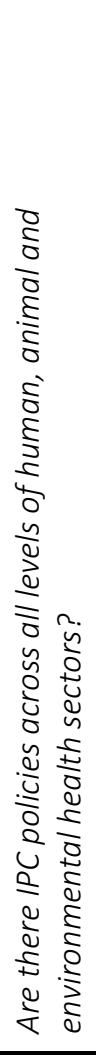 & 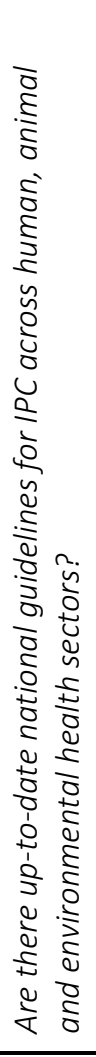 & 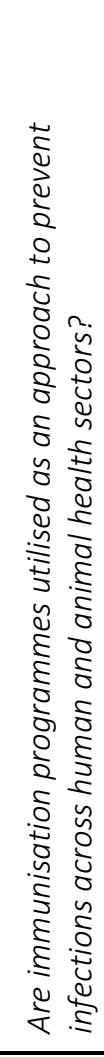 & 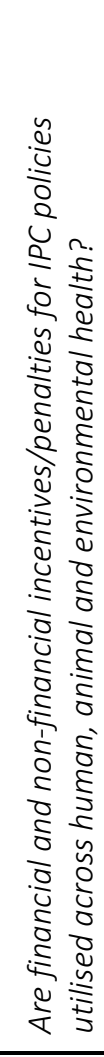 & \multirow{2}{*}{$\begin{array}{l}\text { 을 } \\
\text { 엉 } \\
\text { 궁 } \\
\text { '각 }\end{array}$} & 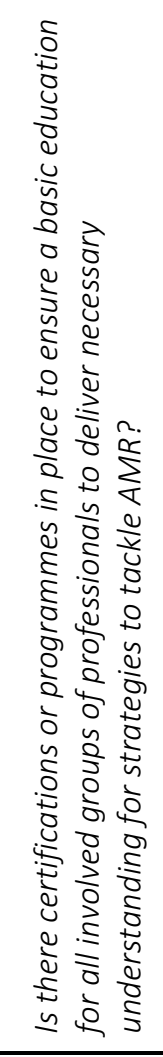 \\
\hline$\widehat{\aleph}$ & & $\stackrel{\text { జ }}{ }$ & ని & 요 & $\vec{m}$ & & $\tilde{m}$ \\
\hline
\end{tabular}




\begin{tabular}{|c|c|c|c|c|c|c|}
\hline \multicolumn{2}{|c|}{ 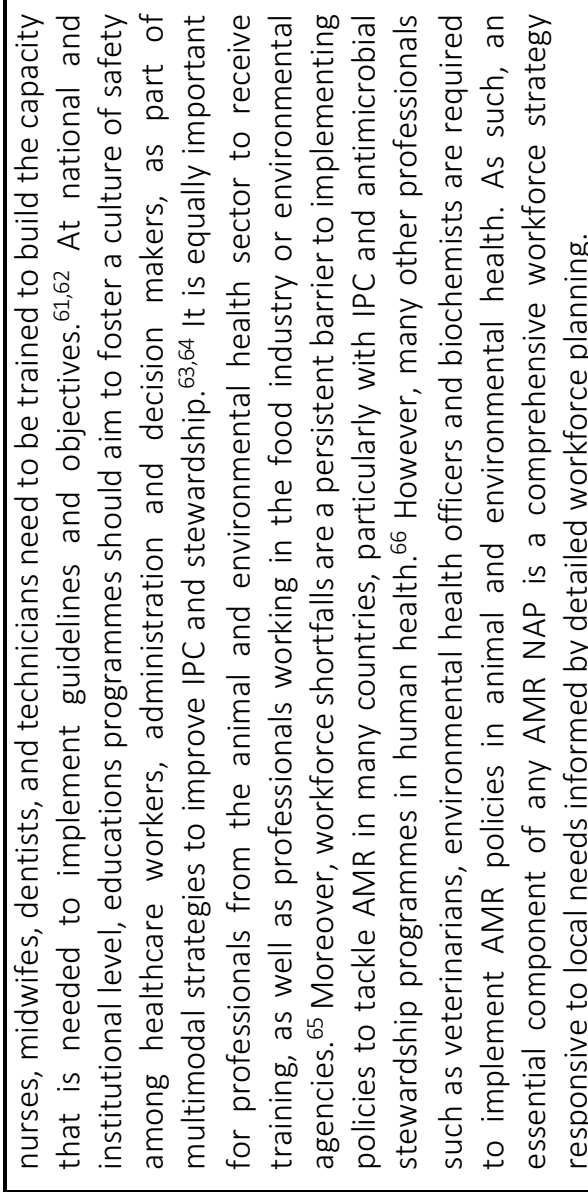 } & \multicolumn{4}{|c|}{ 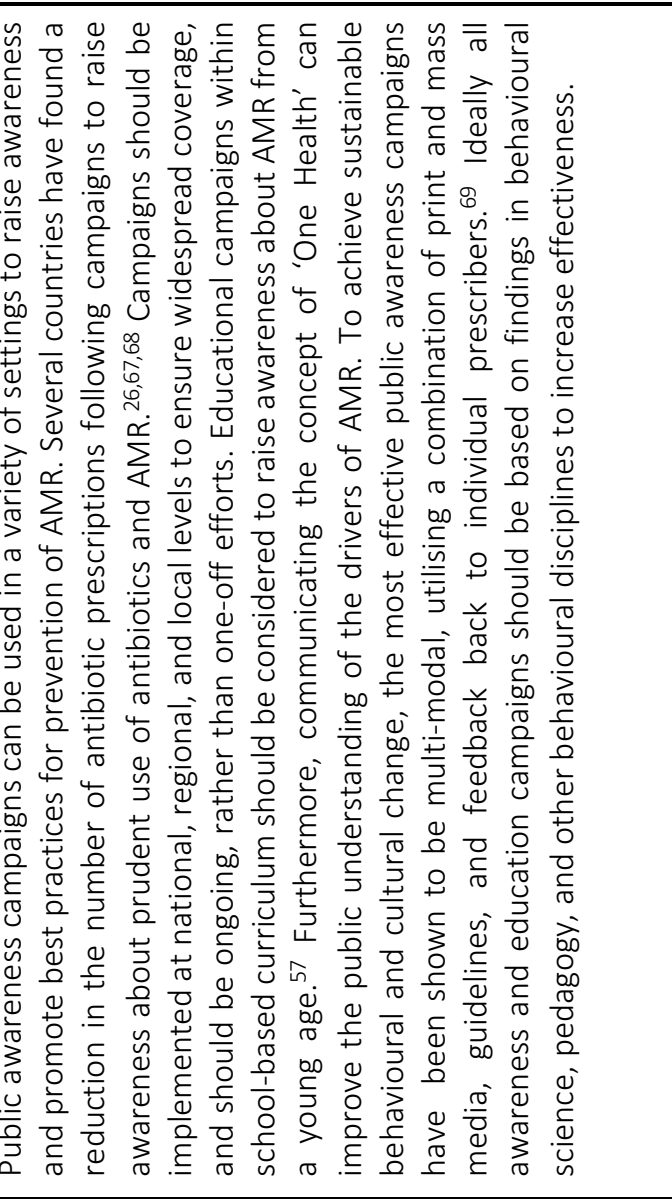 } & 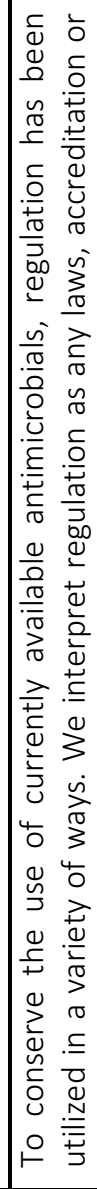 \\
\hline 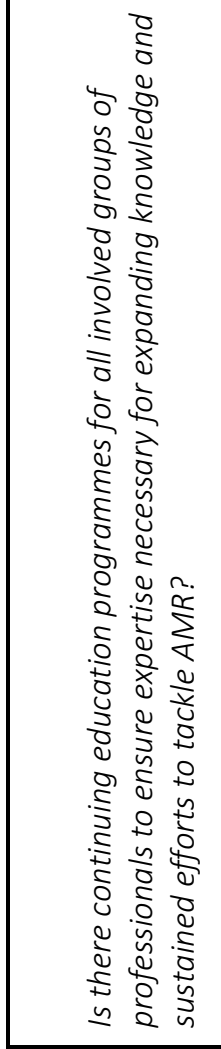 & 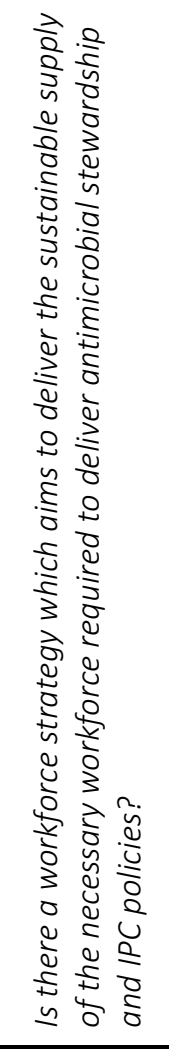 & \multirow{2}{*}{ 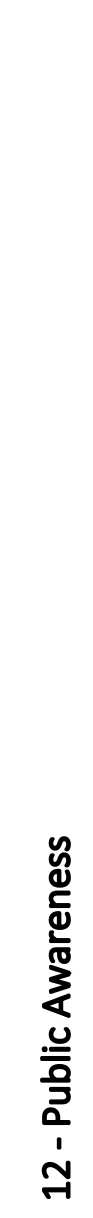 } & 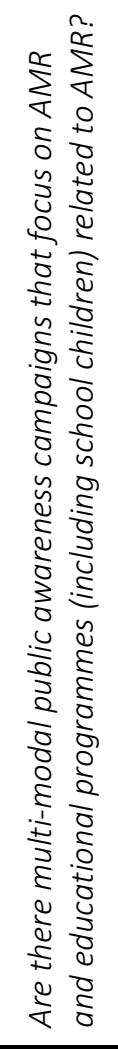 & 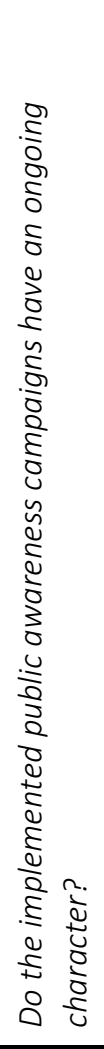 & 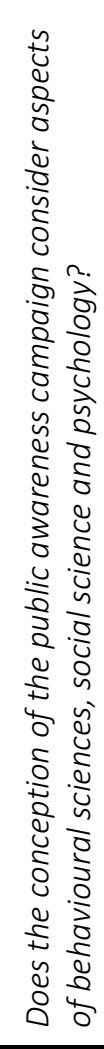 & \multirow{2}{*}{ 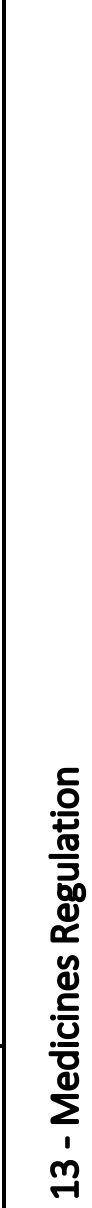 } \\
\hline$\tilde{m}$ & mे & & $\stackrel{\mathscr{m}}{m}$ & $\ddot{m}$ & $\hat{m}$ & \\
\hline
\end{tabular}




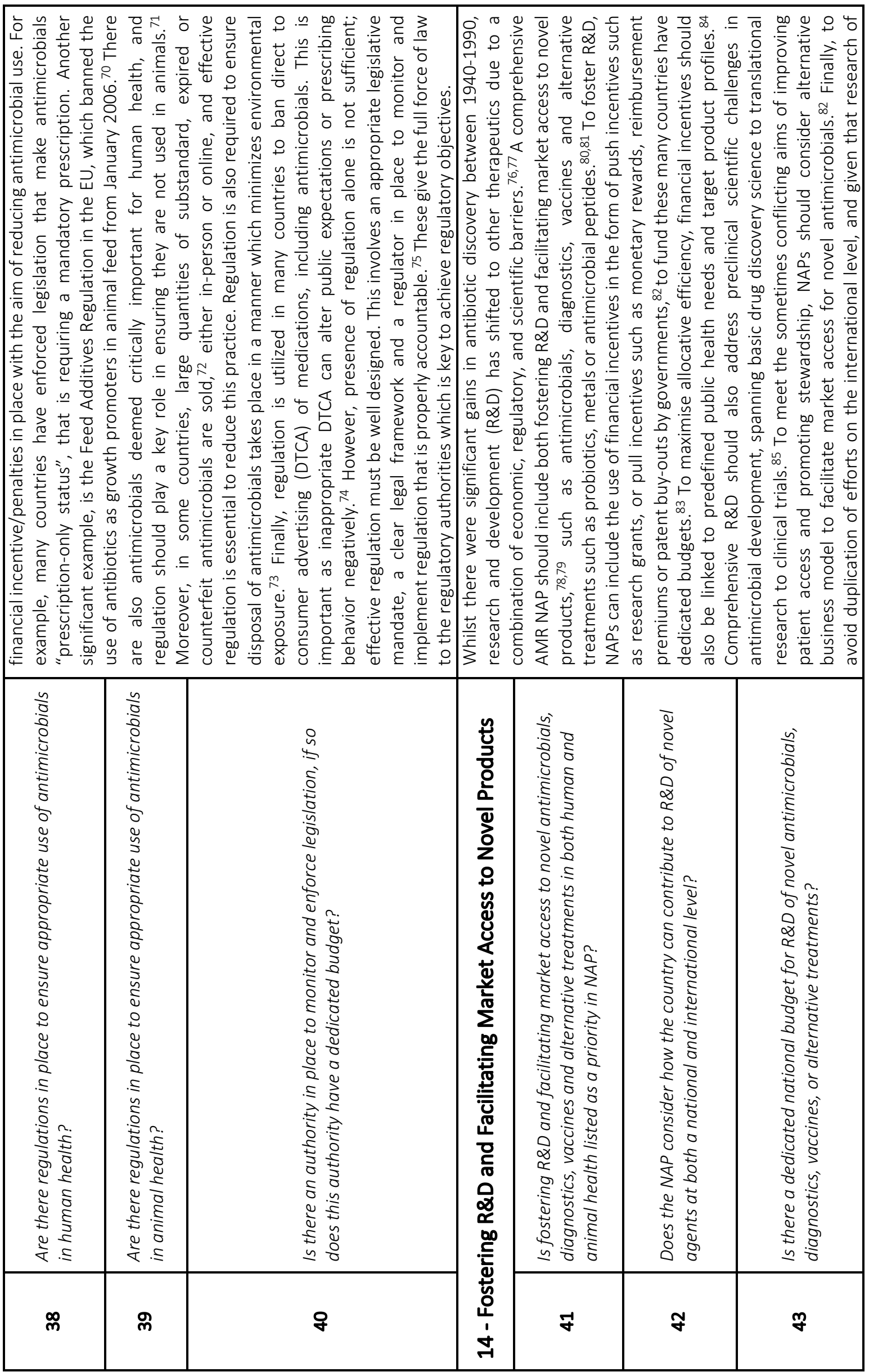




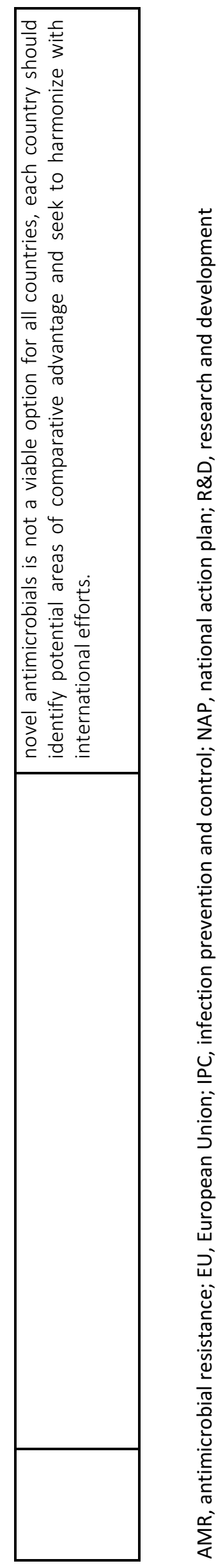




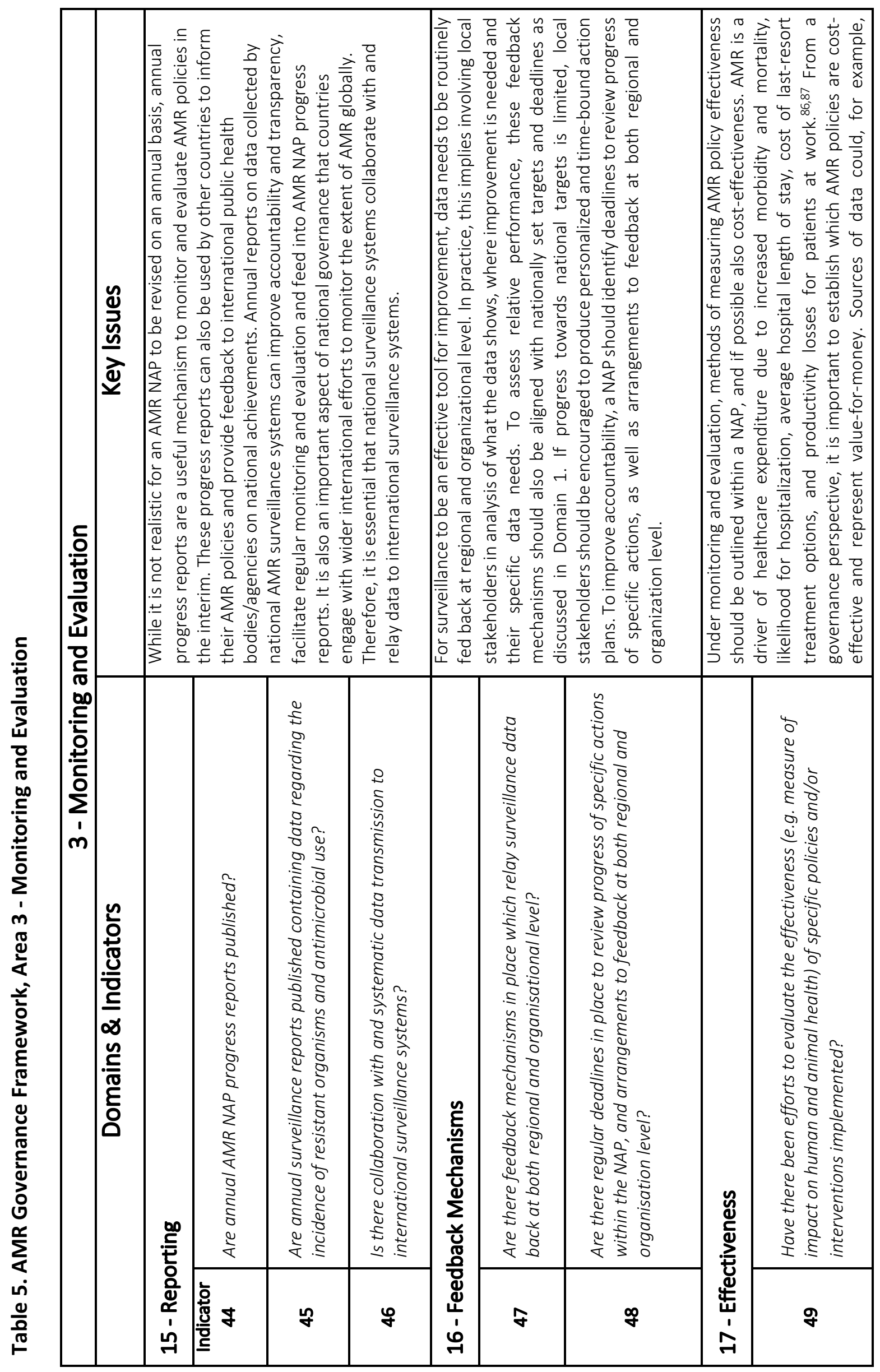




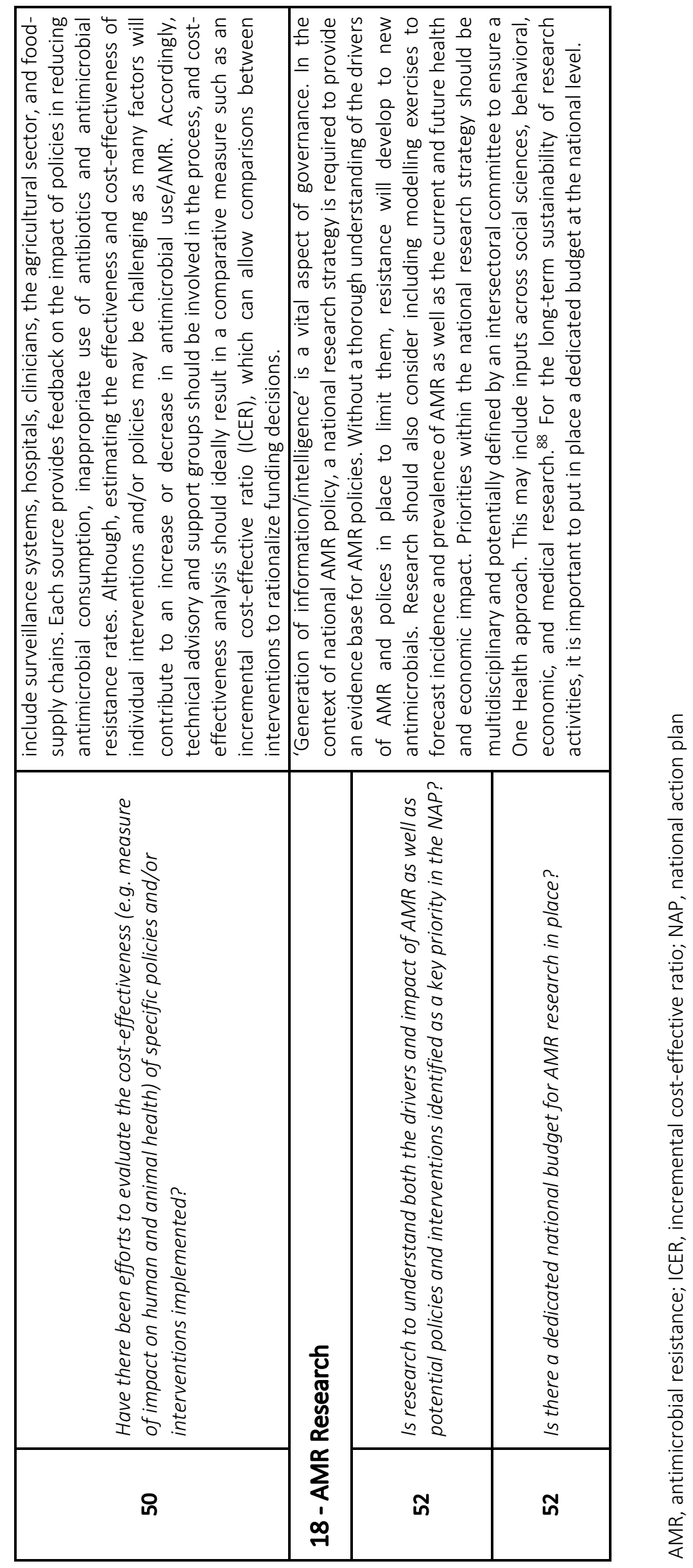


250

251

252

253

254

255

256

257

258

259

260

261

262

263

264

265

266

267

268

269

270

271

272

273

274

275

276

277

278

279

280

281

282

283

A central challenge to combatting the global threat of AMR is the successful implementation, in each country, of an AMR NAP across the relevant sectors and levels, which can be enabled by a systematic approach to governance. Here, we have developed the first comprehensive framework for the governance of AMR NAPs by synthesising findings from a review of health system governance frameworks, an analysis of the guidance from major international organizations, and extensive input from expert policy-makers, practitioners, and researchers from government ministries, international organizations, policy institutes and academic institutions. Within a cyclical design, our governance framework consists of 52 indicators that are contained within 18 domains and grouped in three main governance areas: "policy design", "implementation tools", and "monitoring and evaluation". It is intended to aid policy-makers to design, implement, monitor, and evaluate AMR NAPs across the 'One Health' spectrum, as well as to facilitate objective assessments of countries' AMR NAPs to increase accountability and stimulate debate.

\section{Strengths}

To our knowledge, this is the first study that provides a comprehensive systematic synthesis of available evidence on the governance of AMR NAPs by including information from a systematic review of health system governance frameworks, international guidance, and over 20 experts from various international organizations, government ministries, policy institutes and academic institutions. The AMR governance framework has several strengths. A central and recurring input by experts was the need for usability. By including 52 indicators, and 18 domains the framework balances the right mix of comprehensiveness and usability for policy-makers. This was confirmed by various experts in the fourth stage of the development of the framework. The cyclical design of the framework reflects the dynamic nature of the AMR issue and the corresponding need to be responsive and adaptive, but also ensure that the governance of AMR NAPs itself develops and improves, reflecting the realities observed and lessons learned.

\section{Limitations}

The AMR governance framework also has various limitations. Our review of health system governance frameworks prioritised systematic and non-systematic reviews, therefore it is possible that certain governance frameworks were overlooked. It can also be argued that our AMR governance framework would benefit from either reviewing a larger body of international guidance documents or consulting a larger sample of experts. However, the documents reviewed represent the most recent guidance developed by five major international organisations involved in AMR policy. Furthermore, the expert sample was balanced between international organizations, policy institutes, government, and academia, as well as backgrounds relevant to the 'One Health' approach.

We did not use a structured consensus method during development of the framework. ${ }^{89}$ Our objective is to facilitate international debate around a universally accepted approach to governance in national AMR policy. The establishment of the "One Health Global Leadership Group" on AMR recently recommended by the UN IACG on AMR is one potential forum to develop international consensus. ${ }^{15}$ Alternatively, a more detailed assessment of a county's approach to governance of NAPs could be incorporated into pre-existing initiatives such as the WHO Joint External Evaluation tool, ${ }^{90}$ or the global tripartite database on country progress. 
A further limitation of our AMR governance framework is related to applicability. A thorough objective application of the framework would be resource intensive due to the broad nature of data sources which would need to be reviewed, as well as challenges with data availability as some policy documents or decisions may not be publicly accessible. As a result, several interviews with multiple stakeholders within each country may need to be conducted. This partially explains why current efforts to assess AMR NAPs such as the global tripartite database on country progress revolve around the use of a selfassessment questionnaire. ${ }^{7}$

297

Conversely, it can also be argued that the 52 indicators and 18 domains only provide a superficial assessment in certain areas, and do not assess quality of governance adequately. For example, a country may offer education to all relevant professionals regarding AMR, but it may be of poor quality and brief, or alternatively a public awareness campaign may be in place, but it is poorly financed with a narrow focus. Cross-country comparisons utilising this governance framework should therefore be made with caution as there are possibilities for misleading conclusions.

Finally, the AMR governance framework was developed based upon experience and guidance that applies most typically to high-to-middle income countries. In low income countries with less resources, limited national surveillance and less developed healthcare systems, ${ }^{91,92}$ the application of the framework is possibly ambitious. To address this, we extended the sample size of experts to include perspectives from low-to-middle income countries (LMICs). The feedback was positive, and this resulted in only minor changes to the framework. It was felt this framework was still relevant to lesser developed plans, such as those in some LMICs, as the cyclical nature of this framework captures how shortcomings in pre-existing national action plans can be improved throughout subsequent iterations and repeated applications of the framework.

\section{Conclusion}

Defining and assessing governance of AMR NAPs remains challenging. Despite certain limitations, this AMR governance framework is the first attempt at developing a tool for policy-makers to improve the governance of AMR NAPs, as well as to facilitate the objective assessment of countries' NAPs to increase accountability and stimulate debate.

Disclaimer: The authors alone are responsible for the views expressed in this Article and they do not necessarily represent the views, decisions, or policies of the institutions with which they are affiliated

Contributions: MA, KS and EM conceived the study. MA, KS, AC, DP and EM designed the study. MA and KS drafted the manuscript. AC, DP and EM critically reviewed the paper. All authors contributed to the acquisition, analysis or interpretation of data for the work. All authors approved the final version and agree to be accountable for all aspects of the work.

Declarations of Interest: The authors have no conflicts of interest to disclose.

Funding: This publication draws upon work which was carried out with funding from the European Union. The views expressed herein can in no way be taken to reflect the official position of the European Union

Acknowledgements: We are grateful to Driss Ait Ouakrim, Michele Cecchini and Michael Ryan (Organisation for Economic Co-operation and Development), Charles Clift (Chatham House), Isabel Del La Mata (European Commission), Jeroen Dewulf (Ghent University), Nino Dal Dayanghirang (World 
Health Organization - Regional Office for Africa), Ulrica Dohnhammar (Public Health Agency of Sweden), Scott Greer (University of Michigan), Hanan Hassan Balkhy (World Health Organisation), Ruth Kelly (UK Department of Health and Social Care (at beginning of study), International Centre for Antimicrobial Solutions (currently)), Gabriel Levy Hara (University of Buenos Aires), Dominique L. Monnet (European Centre for Disease Prevention and Control), Folasade Ogunsola (University of Lagos), Mauro Orsini (Ministry of Health of Chile), Tracy Parker (UK, Department of Health and Social Care), Joao Paulo Toledo (Pan American Health Organization), Susanna Sternberg Lewerin (Swedish University of Agricultural Sciences), Minggui Wang (Fudan University), Clare Wenham (London School of Economics and Political Science), Yonghong Xiao (Zhejiang University) who all provided feedback on the governance framework. We are also grateful for the following individuals who both provided feedback and coordinated collective feedback from their respective organisations; Joe Thomas (Antibiotic Resistance Project Team, Pew Charitable Trust), Jennifer Raven (Public Health Agency of Canada), Alexandra Clarici (German Federal Ministry of Health. Federal Ministry of Food and Agriculture, Federal Ministry of Education and Research) and Lawrence Kerr (United States Department of Health and Human Services)

\section{References}

1 The Review on Antimicrobial Resistance. Tackling Drug-Resistant Infections Globally: Final Report and Recommendations. 2016. https://amr-review.org/ (accessed June 16, 2019).

2 Global Action Plan on Antimicrobial Resistance. World Health Organization, 2015. https://www.who.int/antimicrobial-resistance/global-action-plan/en/ (accessed June 16, 2019)

3 Graham J, Amos B, Plumptre T. Principles for good governance in the 21st century. Institute on Governance, Ottawa, 2003.

4 Governance for sustainable human development : a UNDP policy document. United Nations Development Programme, 1997.

5 The World Health Report 2000 - Health Systems: Improving Performance. World Health Organization, 2000. https://www.who.int/whr/2000/en/ (accessed June 16, 2019)

6 Travis P, Egger D, Davies P, Mechbal A. Towards better stewardship: concepts and critical issues Evidence and Information for Policy. World Health Organisation, 2002. https://www.who.int/healthinfo/paper48.pdf (accessed June 19, 2019)

7 Everybody's business: strengthening health systems to improve health outcomes: WHO's framework for action. World Health Organization, 2007. https://www.who.int/healthsystems/strategy/everybodys_business.pdf (accessed June 16, 20190

8 Birgand G, Castro-Sánchez E, Hansen S, et al. Comparison of governance approaches for the control of antimicrobial resistance: Analysis of three European countries. Antimicrobial Resistance and Infection Control. 2018; 7: 28.

9 Wallinga D, Rayner G, Lang T. Antimicrobial resistance and biological governance: explanations for policy failure. Public Health 2015; 129: 1314-25.

10 Prudent use of antimicrobial agents in human medicine: third report on implementation of the Council recommendation. European Commission Directorate-General for Health and 
Food Safety, 2016 https://ec.europa.eu/health/amr/sites/amr/files/amr_projects_3rd-reportcouncilrecprudent.pdf (accessed June 16, 2019)

11 Antimicrobial resistance - A manual for developing national action plans, WHO, FAO, OIE. 2016. https://www.who.int/antimicrobial-resistance/national-action-plans/manual/en/ (accessed June 16, 2019)

12 Country progress in the implementation of the global action plan on antimicrobial resistance: WHO, FAO and OIE global tripartite database, WHO, FAO, OIE. http://www.who.int/antimicrobial-resistance/global-action-plan/database/en/ (accessed June 19, 2019).

13. Antimicrobial resistance: national action plans IACG Discussion Paper 1. UN Interagency Coordination Group on Antimicrobial Resistance, 2018 https://www.who.int/antimicrobial-resistance/interagency-coordinationgroup/IACG_AMR_National_Action_Plans_110618.pdf?ua=1 (accessed June 16, 2019)

14AMR Framework for Action. UN Interagency Coordination Group on Antimicrobial Resistance, 2017. https://www.who.int/antimicrobial-resistance/interagency-coordinationgroup/20170818_AMR_FfA_v01.pdf?ua=1 (accessed June 22, 2019).

15 .No Time to Wait: Securing the Future from Drug-Resistant Infections. Report to the Secretary-General of the United Nations. UN Interagency Coordination Group on Antimicrobial Resistance, 2019. https://www.who.int/antimicrobialresistance/interagency-coordination-group/IACG_final_report_EN.pdf?ua=1 (accessed June 16, 2019).

16 The OIE Strategy on Antimicrobial Resistance and the Prudent Use of Antimicrobials. World Organisation for Animal Health, 2016. http://www.oie.int/fileadmin/Home/eng/Media_Center/docs/pdf/PortailAMR/EN_OIEAMRstrategy.pdf (accessed June 16, 2019)

17 The FAO Action Plan on Antimicrobial Resistance 2016-2020. Food and Agriculture Organization of the United Nations, 2016. http://www.fao.org/3/a-i5996e.pdf (accessed June 16, 2019)

18 A European One Health Action Plan against Antimicrobial Resistance (AMR). European Commission, 2017. https://ec.europa.eu/health/amr/sites/amr/files/amr_action_plan_2017_en.pdf (accessed June 16, 2019)

19Marshall MN. Sampling for qualitative research. Family practice 1996; 13: 522-5.

20 Pyone T, Smith H, van den Broek N. Frameworks to assess health systems governance: a systematic review. Health policy and planning 2017; 32: 710-22.

21 Mikkelsen-Lopez I, Wyss K, de Savigny D. An approach to addressing governance from a health system framework perspective. BMC International Health and Human Rights 2011; 11: 13 .

22 Barbazza E, Tello JE. A review of health governance: Definitions, dimensions and tools to govern. Health Policy 2014; 116: 1-11. 
23 Greer SL. Governance: A framework. Chapter 2 in Strengthening Health System Governance: Better policies, stronger performance. European Observatory on Health Systems and Policies Series. McGraw Hill Education. Open University Press. 2014.

24Laxminarayan R, Duse A, Wattal C, et al. Antibiotic resistance-the need for global solutions. The Lancet Infectious diseases 2013; 13: 1057-98.

25 Hoffman SJ, Caleo GM, Daulaire N, et al. Strategies for achieving global collective action on antimicrobial resistance. Bulletin of the World Health Organization 2015; 93: 867-76.

26 Dar OA, Hasan R, Schlundt J, et al. Exploring the evidence base for national and regional policy interventions to combat resistance. Lancet. 2016; 387: 285-95.

27 Schuts EC, Hulscher MEJL, Mouton JW, et al. Current evidence on hospital antimicrobial stewardship objectives: a systematic review and meta-analysis. The Lancet Infectious Diseases 2016; 16: 847-56.

28 One Health Mission Statement. One Health Initiative. http://www.onehealthinitiative.com/mission.php (accessed June 16, 2019)

29Brinkerhoff DW. Accountability and health systems: toward conceptual clarity and policy relevance. Health Policy and Planning 2004; 19: 371-9.

30 Uchil RR, Kohli GS, Katekhaye VM, Swami OC. Strategies to combat antimicrobial resistance. Journal of clinical and diagnostic research: JCDR 2014; 8: ME01-4.

31 National health policies, strategies and plans. World Health Organisation. http://www.who.int/nationalpolicies/vision/en/ (accessed June 16, 2019).

32 National Action Plan for Health Security. World Health Organisation. http://www.who.int/ihr/procedures/health-security-national-action-plan/en/ (accessed June $16,2019)$.

33 van der Heijden M, Sandgren A, Pränting M, et al. When the Drugs Don't Work: Antibiotic Resistance as a Global Development Problem. ReAct. https://www.reactgroup.org/wp-content/uploads/2019/02/When-the-DrugsDon\%E2\%80\%99t-Work-Antibiotic-Resistance-as-a-Global-Development-Problem-Feb2019.pdf (accessed June 16, 2019).

34 Monnier AA, Schouten J, Tebano G, et al. Ensuring Antibiotic Development, Equitable Availability, and Responsible Use of Effective Antibiotics: Recommendations for Multisectoral Action. Clin Infect Dis 2019; 68: 1952-9.

35 Cox JA, Vlieghe E, Mendelson M, et al. Antibiotic stewardship in low- and middleincome countries: the same but different? Clin Microbiol Infect 2017; 23: 812-8.

36 Malan L, Labuschagne Q, Brechtelsbauer E, Goff DA, Schellack N. Sustainable Access to Antimicrobials; A Missing Component to Antimicrobial Stewardship-A Tale of Two Countries. Front Public Health 2018; 6: 324. 
37 Alsan M, Schoemaker L, Eggleston K, Kammili N, Kolli P, Bhattacharya J. Out-of-pocket health expenditures and antimicrobial resistance in low-income and middle-income countries: an economic analysis. Lancet Infect Dis 2015; 15: 1203-10.

38 Okeke IN, Klugman KP, Bhutta ZA, et al. Antimicrobial resistance in developing countries. Part II: strategies for containment. Lancet Infect Dis 2005; 5: 568-80.

39 Versporten A, Gyssens IC, Pulcini C, et al. Metrics to assess the quantity of antibiotic use in the outpatient setting: a systematic review followed by an international multidisciplinary consensus procedure. J Antimicrob Chemother 2018; 73: vi59-66.

40 Altorf-van der Kuil W, Schoffelen AF, de Greeff SC, et al. National laboratory-based surveillance system for antimicrobial resistance: a successful tool to support the control of antimicrobial resistance in the Netherlands. Euro Surveill 2017; 22.

41 Schrijver R, Stijntjes M, Rodríguez-Baño J, Tacconelli E, Babu Rajendran N, Voss A. Review of antimicrobial resistance surveillance programmes in livestock and meat in EU with focus on humans. Clin Microbiol Infect 2018; 24: 577-90.

42 Schar D, Sommanustweechai A, Laxminarayan R, Tangcharoensathien V. Surveillance of antimicrobial consumption in animal production sectors of low- and middle-income countries: Optimizing use and addressing antimicrobial resistance. PLoS Med 2018; 15: e1002521.

43 Seale AC, Gordon NC, Islam J, Peacock SJ, Scott JAG. AMR Surveillance in low and middle-income settings - A roadmap for participation in the Global Antimicrobial Surveillance System (GLASS). Wellcome Open Res 2017; 2: 92.

44 Dyar OJ, Huttner B, Schouten J, Pulcini C, ESGAP (ESCMID Study Group for Antimicrobial stewardshiP). What is antimicrobial stewardship? Clinical microbiology and infection: the official publication of the European Society of Clinical Microbiology and Infectious Diseases 2017.

45 Pulcini C, Binda F, Lamkang AS, et al. Developing core elements and checklist items for global hospital antimicrobial stewardship programmes: a consensus approach. Clin Microbiol Infect 2019; 25: 20-5.

46 Landers TF, Cohen B, Wittum TE, Larson EL. A Review of Antibiotic Use in Food Animals: Perspective, Policy, and Potential. Public Health Rep 2012; 127: 4-22.

47 Teale CJ, Moulin G. Prudent use guidelines: a review of existing veterinary guidelines. Rev - Off Int Epizoot 2012; 31: 343-54.

48 Bou-Antoun S, Costelloe C, Honeyford K, et al. Age-related decline in antibiotic prescribing for uncomplicated respiratory tract infections in primary care in England following the introduction of a national financial incentive (the Quality Premium) for health commissioners to reduce use of antibiotics in the community: an interrupted time series analysis. J Antimicrob Chemother 2018; 73: 2883-92.

49 Meeker D, Linder JA, Fox CR, et al. Effect of Behavioral Interventions on Inappropriate Antibiotic Prescribing Among Primary Care Practices: A Randomized Clinical Trial. JAMA 2016; 315: 562-70. 
50 Tängdén T, Pulcini C, Aagaard H, et al. Unavailability of old antibiotics threatens effective treatment for common bacterial infections. Lancet Infect Dis 2018; 18: 242-4.

51 Baur D, Gladstone BP, Burkert F, et al. Effect of antibiotic stewardship on the incidence of infection and colonisation with antibiotic-resistant bacteria and Clostridium difficile infection: a systematic review and meta-analysis. Lancet Infect Dis 2017; 17: 990-1001.

52 Storr J, Twyman A, Zingg W, et al. Core components for effective infection prevention and control programmes: new WHO evidence-based recommendations. Antimicrob Resist Infect Control 2017; 6: 6.

53 Guidelines on core components of infection prevention and control programmes at the national and acute health care facility level. World Health Organisation, 2016. https://www.who.int/gpsc/ipc-components-guidelines/en/ (accessed June 22, 2019).

54 Allegranzi B, Gayet-Ageron A, Damani N, et al. Global implementation of WHO's multimodal strategy for improvement of hand hygiene: a quasi-experimental study. The Lancet Infectious Diseases 2013; 13: 843-51.

55 Laanen M, Persoons D, Ribbens S, et al. Relationship between biosecurity and production/antimicrobial treatment characteristics in pig herds. Vet $J$ 2013; 198: 508-12.

56 Huijbers PMC, Blaak H, de Jong MCM, Graat EAM, Vandenbroucke-Grauls CMJE, de Roda Husman AM. Role of the Environment in the Transmission of Antimicrobial Resistance to Humans: A Review. Environ Sci Technol 2015; 49: 11993-2004.

57 Singer AC, Shaw H, Rhodes V, Hart A. Review of Antimicrobial Resistance in the Environment and Its Relevance to Environmental Regulators. Frontiers in microbiology 2016; 7: 1728.

58 Haustein T, Gastmeier P, Holmes A, et al. Use of benchmarking and public reporting for infection control in four high-income countries. Lancet Infect Dis 2011; 11: 471-81.

59Drohan SE, Levin SA, Grenfell BT, Laxminarayan R. Incentivizing hospital infection control. PNAS 2019; 116: 6221-5.

60 Clift C, Salisbury DM. Enhancing the role of vaccines in combatting antimicrobial resistance. Vaccine 2017; 35: 6591-3.

61 Pulcini C, Wencker F, Frimodt-Møller N, et al. European survey on principles of prudent antibiotic prescribing teaching in undergraduate students. Clin Microbiol Infect 2015; 21: 354-61.

62 Pulcini C, Gyssens IC. How to educate prescribers in antimicrobial stewardship practices. Virulence 2013; 4: 192-202.

63 Improving infection prevention and control at the health facility: interim practical manual supporting implementation of the WHO guidelines on core components of infection prevention and control programmes. World Health Organisation, 2018. https://apps.who.int/iris/handle/10665/279788 (accessed June 22, 2019). 
64 Interim Practical Manual supporting national implementation of the WHO Guidelines on Core Components of Infection Prevention and Control Programmes. World Health Organiation, 2017. https://www.who.int/infection-prevention/tools/core-components/ccimplementation-guideline.pdf (accessed June 22, 2019).

65 Thomas G. Tackling antibiotic resistance in veterinary practice: a team approach. The Veterinary Nurse 2015; 6: 298-301.

66Zingg W, Holmes A, Dettenkofer M, et al. Hospital organisation, management, and structure for prevention of health-care-associated infection: a systematic review and expert consensus. The Lancet Infectious Diseases 2015; 15: 212-24.

67Filippini M, Ortiz LGG, Masiero G. Assessing the impact of national antibiotic campaigns in Europe. The European Journal of Health Economics 2013; 14: 587-99.

68 Goossens H. European Strategies to Control Antibiotic Resistance and Use. Annals of Clinical Microbiology 2014; 17: 1.

69 Ashiru-Oredope D, Hopkins S. Antimicrobial resistance: moving from professional engagement to public action. $J$ Antimicrob Chemother 2015; 70: 2927-30.

70 European Parliament and the Council of 22 September 2003. Regulation (EC) 1831/2003 on additives for use in animal nutrition. 2003. https://eur-lex.europa.eu/legalcontent/EN/TXT/?uri=CELEX\%3A32003R1831 (accessed June 16, 2019)

71 Critically important antimicrobials for human medicine 6th Edition. World Health Organisation, 2018. http://www.who.int/foodsafety/areas_work/antimicrobialresistance/cia/en/ (accessed June 16, 2019).

72 Kelesidis T, Falagas ME. Substandard/Counterfeit Antimicrobial Drugs. Clin Microbiol Rev 2015; 28: 443-64.

73 Pruden A, Larsson DGJ, Amézquita A, et al. Management Options for Reducing the Release of Antibiotics and Antibiotic Resistance Genes to the Environment. Environ Health Perspect 2013; 121: 878-85.

74 Almasi EA, Stafford RS, Kravitz RL, Mansfield PR. What Are the Public Health Effects of Direct-to-Consumer Drug Advertising? PLoS Med 2006; 3.

75 Baldwin R, Cave Martin, Lodge M. Understanding regulation: theory, strategy, and practice. Second Edition. Oxford University Press, 2012

76 Silver LL. Challenges of antibacterial discovery. Clinical microbiology reviews 2011; 24 : 71-109.

77 A Scientific Roadmap for Antibiotic Discovery. Pew Charitable Trusts, 2016. https://www.pewtrusts.org/en/research-and-analysis/reports/2016/05/a-scientific-roadmapfor-antibiotic-discovery (accessed June 16, 2019)

78 Brogan DM, Mossialos E. Incentives for new antibiotics: the Options Market for Antibiotics (OMA) model. Global Health 2013; 9: 58. 
79 Brogan DM, Mossialos E. Systems, not pills: The options market for antibiotics seeks to rejuvenate the antibiotic pipeline. Soc Sci Med 2016; 151: 167-72.

80 Cheng G, Hao H, Xie S, et al. Antibiotic alternatives: the substitution of antibiotics in animal husbandry? Frontiers in microbiology 2014; 5: 217.

81 Allen HK, Trachsel J, Looft T, Casey TA. Finding alternatives to antibiotics. Annals of the New York Academy of Sciences 2014; 1323: 91-100.

82 Renwick MJ, Brogan DM, Mossialos E. A systematic review and critical assessment of incentive strategies for discovery and development of novel antibiotics. The Journal of Antibiotics 2016; 69: 73-88.

83 Simpkin VL, Renwick MJ, Kelly R, Mossialos E. Incentivising innovation in antibiotic drug discovery and development: progress, challenges and next steps. J Antibiot 2017; 70: 1087-96.

84 Mossialos E, Morel C, Edwards S, Berenson J, Gemmill-Toyama M, Brogan D. Policies and incentives for promoting innovation in antibiotic research. European Observatory on Health Systems and Policies, 2010. http://www.euro.who.int/en/aboutus/partners/observatory/publications/studies/policies-and-incentives-for-promotinginnovation-in-antibiotic-research-2010 (accessed June 22, 2019).

85 Renwick M, Mossialos E. What are the economic barriers of antibiotic R\&D and how can we overcome them? Expert Opinion on Drug Discovery 2018; 13: 889-92.

86 Kaier K, Wilson C, Chalkley M, et al. Health and Economic Impacts of Antibiotic Resistance in European Hospitals - Outlook on the BURDEN Project. Infection 2008; 36: 492-4.

87 Taylor J, Hafner M, Yerushalmi E, et al. Estimating the economic costs of antimicrobial resistance: Model and Results. RAND, 2014. https://www.rand.org/pubs/research_reports/RR911.html (accessed June 16, 2019)

88 Rzewuska M, Charani E, Clarkson JE, et al. Prioritizing research areas for antibiotic stewardship programmes in hospitals: a behavioural perspective consensus paper. Clin Microbiol Infect 2019; 25: 163-8.

89 McMillan SS, King M, Tully MP. How to use the nominal group and Delphi techniques. Int J Clin Pharm 2016; 38: 655-62.

90 Joint External Evaluation tool (JEE tool) - second edition. IHR (2005) Monitoring and Evaluation framework. World Health Organisation, 2018. http://www.who.int/ihr/publications/WHO_HSE_GCR_2018_2/en/ (accessed June 16, 2019).

91 Tadesse BT, Ashley EA, Ongarello S, et al. Antimicrobial resistance in Africa: a systematic review. BMC Infectious Diseases 2017; 17: 616.

92 Mshana SE, Matee M, Rweyemamu M. Antimicrobial resistance in human and animal pathogens in Zambia, Democratic Republic of Congo, Mozambique and Tanzania: an 
600 urgent need of a sustainable surveillance system. Ann Clin Microbiol Antimicrob 2013; 12:

601 28.

602

603 